\title{
Effect of Heating on the Color Formation Reaction in the Murphy and Riley Method for the Determination of Phosphate in Natural Waters
}

\author{
Su-Cheng Pai ${ }^{1 *}$, Tzu-Yuan Wang ${ }^{1}$, Tien-Hsi Fang ${ }^{2}$ and Kuo-Tung Jiann ${ }^{3}$ \\ ${ }^{1}$ Institute of Oceanography, National Taiwan University, Taipei, Taiwan \\ ${ }^{2}$ Department of Marine Environmental Informatics, National Taiwan Ocean University, Keelung, Taiwan \\ ${ }^{3}$ Department of Oceanography, National Sun Yat-Sen University, Kaohsiung, Taiwan
}

\begin{abstract}
Heating is frequently applied to enhance the reaction rate for the determination of phosphate but it may cause unexpected errors. Experiments show that the spectrum of the blue color produced by the Murphy and Riley method is subject to change at different temperatures. The variation of the molar extinction coefficient at $880 \mathrm{~nm}$ was found to be $-48 \mathrm{M}^{-1} \mathrm{~cm}^{-1} \mathrm{C}^{-1}$, or a relative trend of -0.22 $\%{ }^{\circ} \mathrm{C}^{-1}$ w.r.t. to the absorbance at $30^{\circ} \mathrm{C}$. When the color formation reaction took place at $>35^{\circ} \mathrm{C}$, the absorbance started to climb. At temperatures $>60^{\circ} \mathrm{C}$, the results were erratic and the change becomes irreversible. These findings suggest that the measurement should be made at room temperature and any heating process above $35^{\circ} \mathrm{C}$ should be avoided. A thermostated cuvette holder set at $30^{\circ} \mathrm{C}$ is highly recommended for both manual and flow type operation.
\end{abstract}

Keywords: Phosphate; Spectrum; Heating; Color formation reaction

\section{Introduction}

The molybdate-ascorbic acid method developed by Murphy and Riley [1] for the determination of phosphate in natural waters has been widely adopted in many scientific disciplines [2-4]. When the manual procedure is converted to an automated operation, heating is frequently applied to enhance the rate of color formation reaction for a fast throughput. For example, APHA/AWWA/WEF Standard Methods have suggested an on-line $37^{\circ} \mathrm{C}$ water bath [5]; Johnson and Petty [6] have employed a $50^{\circ} \mathrm{C}$ bath; and in an extreme case, a $95^{\circ} \mathrm{C}$ reactor has been used by Yuchi et al. [7]. Although heating can effectively improve the reaction rate $[8,9]$, some scientists have encountered other problems. Benson et al. [10] have reported a phenomenon where the peak signals decreased significantly when the bath temperature was raised up to $60^{\circ} \mathrm{C}$; Drummond and Maher [11] and Zhang et al. [12] have both observed noticeable silicate interferences at elevated temperatures. They have suggested that the determination should be preferably performed at room temperature.

However, we have encountered a dilemma on whether or not one should apply an on-line heating device. On our past expedition cruises, seawater samples were collected from different depths (e.g. from surface to $>3000 \mathrm{~m}$ deep with original temperatures from $30^{\circ} \mathrm{C}$ down to $2^{\circ} \mathrm{C}$ ) and all nutrients including phosphate were measured on-board by a flow injection system within 1 hour after retrieving the sampler to the deck. The use of an on-line heating bath could largely minimize the large temperature differences between samples and standards, but the uncertainty induced has yet been well evaluated. In order to clarify this problem, a series of heating experiment was carried out at higher concentrations $(30-50 \mu \mathrm{M})$ in order to magnify the variation. The results will provide field analysts a quantified measure of the heating effect so they are able to choose a proper way to avoid such an uncertainty.

\section{Material and Methods}

\section{Reagents}

Mixed reagent (HMoSb): A $200 \mathrm{~mL}$ molybdate solution (containing $5.1 \mathrm{~g}$ of ammonium molybdate heptahydrate) was poured gradually while stirring into a beaker filled with $180 \mathrm{~mL}$ of conc. sulfuric acid, followed by mixing a $100 \mathrm{~mL}$ of the antimony solution (containing $0.5 \mathrm{~g}$ of potassium antimony tartrate). The final volume was made up to $500 \mathrm{~mL}$.

Ascorbic acid reagent (ASC): An amount of $13.2 \mathrm{~g}$ of L-ascorbic acid was dissolved in $250 \mathrm{~mL}$ of double distilled water.
Phosphate standard: A $10 \mathrm{mM}$ P stock solution was prepared by dissolving $0.1361 \mathrm{~g}$ of $\mathrm{KH}_{2} \mathrm{PO}_{4}$ in $1 \mathrm{~L}$ of double distilled water. Diluted working standards were prepared from this stock solution.

Spiked seawater: A filtered surface seawater (salinity $=33.4 \mathrm{psu}$ ) was prepared previously. The original concentration was $<0.05 \mu \mathrm{M}$ P. An aliquot of $3 \mathrm{~mL}$ of the stock standard solution was added to this seawater to make a final volume of $1 \mathrm{~L}$ to give a spiking concentration of $30 \mu \mathrm{M}$.

Reagent strengths: The reagent strengths used in this study were slightly different from the original recipe [1] with a lower acidity to minimize $\mathrm{Si}$ interference and higher $\mathrm{Sb}^{3+}$ and ASC concentrations to increase the reaction rate $[11,12]$. When $2 \mathrm{~mL}$ of $\mathrm{HMoSb}$ reagent and $1 \mathrm{~mL}$ of ASC reagent are added to a $25 \mathrm{~mL}$ aliquot of sample, the final reagent strengths are: $[\mathrm{Mo}]=4.13 \mathrm{mM} ;\left[\mathrm{H}^{+}\right]=309 \mathrm{mM} ;\left[\mathrm{Sb}^{3+}\right]=0.213$ $\mathrm{mM} ;[\mathrm{ASC}]=10.7 \mathrm{mM}$, with a $\left[\mathrm{H}^{+}\right] /[\mathrm{Mo}]$ ratio of 74.8 .

\section{Apparatus}

A Shimadzu UV1800 spectrophotometer was equipped with a temperature-controlled cuvette holder (Shimadzu T-83400-52) connected to a thermostat water circulation bath (Firstek B401H) with a $1 \mathrm{~kW}$ heater and a $700 \mathrm{~W}$ cooler (Figure 1). A dome-type flow cuvette (Hellma, $1 \mathrm{~cm}$ length, $450 \mu \mathrm{L}$ capacity) was used. The sample solution was placed in a reaction bottle immersed in a second thermostat water bath (Firstek B206) and controlled by a $750 \mathrm{~W}$ heater. The sample could be quickly taken up by a peristaltic pump to fill up the cuvette in $10 \mathrm{~s}$.

\section{Experiment designs}

Exp-1 Absorption spectra: A fully-developed blue color solution was transferred to the cuvette for scanning from 950 to $650 \mathrm{~nm}$ at different temperatures. The absorbance at $880 \mathrm{~nm}$ was recorded along a time scale while the thermostat was heated up step-wisely from 15 to $90^{\circ} \mathrm{C}$, then cooled back down to $15^{\circ} \mathrm{C}$.

*Corresponding author: Su-Cheng Pai, Institute of Oceanography, National Taiwan University, Taipei, Taiwan, Tel: 886922227358; E-mail: scpai@ntu.edu.tw

Received April 30, 2015; Accepted May 12, 2015; Published May 20, 2015

Citation: Pai S, Wang T, Fang T, Jiann K (2015) Effect of Heating on the Color Formation Reaction in the Murphy and Riley Method for the Determination of Phosphate in Natural Waters. J Environ Anal Chem 2: 139. doi:10.4172/2380-2391.1000139

Copyright: @ 2015 Pai S et al. This is an open-access article distributed under the terms of the Creative Commons Attribution License, which permits unrestricted use, distribution, and reproduction in any medium, provided the original author and source are credited. 


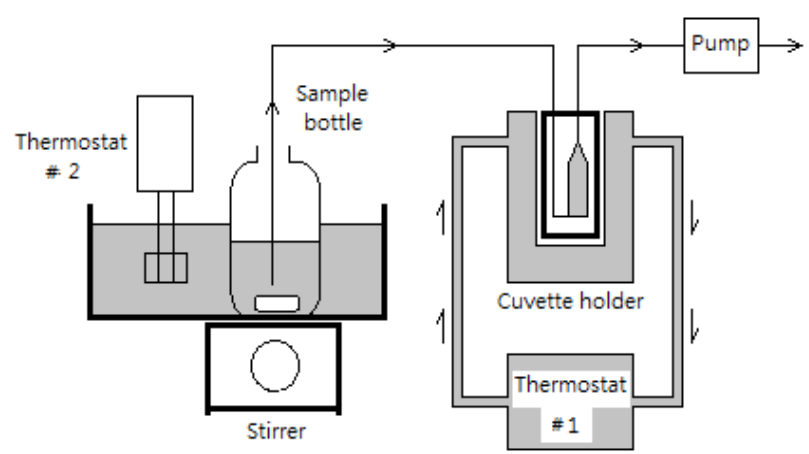

Figure 1: Apparatus used to monitor the color formation reaction in this study. The system has two thermostat baths (\#1 and \#2). The first one is connected to a water-circulating cuvette holder installed in a Shimadzu UV1800 spectrophotometer. A dome-type Hellma flow cuvette $(1 \mathrm{~cm}, 450 \mu \mathrm{L})$ is inserted into the holder. The sample is placed in a bottle immersed in a second thermostat. Upon adding reagents, the mixture is quickly taken up to fill the cuvette by a peristaltic pump at a rate of $20 \mathrm{~mL} \mathrm{~min}^{-1}$

Exp-2 Color formation at fixed temperatures: Both thermostats were adjusted to the same temperature. The reagent added sample was immediately transferred to the flow cuvette then trapped for observation of the formation curve.

Exp-3 Color formation at elevating temperature: The starting temperature was set at $25^{\circ} \mathrm{C}$ but the cuvette holder was heated up to $30-$ $90^{\circ} \mathrm{C}$ at $15^{\circ} \mathrm{C}$ intervals. The sample added with reagents was transferred immediately to the heated flow cuvette. The color formation curve obtained this way was under a temperature-ramping condition.

\section{Results and Discussion}

\section{Spectra at different temperatures}

In Exp-1 two color-fully-developed phosphomolybdenum blue solutions ( $50 \mu \mathrm{M}$ in freshwater and $30 \mu \mathrm{M}$ in seawater) were scanned at different temperatures and the overlapped absorption spectra are shown in Figure 2. The change of spectra due to temperature was significant, and a knot at a wavelength of $935 \mathrm{~nm}$ was found for both media. On the left-hand side of this knot the absorption patterns became lower as temperature increased, and vice versa.

The observation on the effect of changing temperature to the molar extinction coefficient at $880 \mathrm{~nm}$ is shown in Figure 3. The blue colored solution was again transferred to fill the cuvette. The cuvette holder was first cooled down to $15^{\circ} \mathrm{C}$, and then the thermostat was heated up in a step-wise manner at $5^{\circ} \mathrm{C}$ intervals. As temperature increased, the absorbance decreased like a mirror image. The molar extinction coefficient at $880 \mathrm{~nm}$ was found to be 23400, 22850, 22600, 21700 $\ldots 19800 \mathrm{M}^{-1} \mathrm{~cm}^{-1}$ at $15,25,30,50 \ldots 90^{\circ} \mathrm{C}$, respectively. The slope of variation was found to be $-48 \mathrm{M}^{-1} \mathrm{~cm}^{-1{ }^{\circ}} \mathrm{C}^{-1}$ (Figure 4) or a relative trend of $-0.22 \%{ }^{\circ} \mathrm{C}^{-1}$ w.r.t. the absorbance value at $30^{\circ} \mathrm{C}$. After reaching the highest $90^{\circ} \mathrm{C}$, the cooler of the thermostat was switched on and the temperature was dropped also in a step-wise manner. At the ending $15^{\circ} \mathrm{C}$ the absorbance went back to almost the identical value as that of the starting $15^{\circ} \mathrm{C}$. In the seawater medium the trend and slope were almost the same as that in freshwater. The change due to temperature variation was apparently reversible in this experiment.

\section{Color formation reaction at fixed temperatures}

In Exp-2 the color formation reaction took place at fixed temperatures $\left(20,25,30,35\right.$ and $\left.45^{\circ} \mathrm{C}\right)$ and the results are presented in Figure 5. At $20^{\circ} \mathrm{C}$ the curve was an " $\mathrm{S}$ " shape with a slow beginning, followed by an accelerating stage and then a slow ending. The time for reaching $90 \%$ of maximum absorbance $\left(\mathrm{t}_{90 \%}\right)$ was $62 \mathrm{~s}$ at $20^{\circ} \mathrm{C}$, reduced to 38 and $24 \mathrm{~s}$ at 25 and $30^{\circ} \mathrm{C}$, with $-1 \%$ and $-2 \%$ lower absorbances. At $45^{\circ} \mathrm{C}$, the reaction was very fast $\left(\mathrm{t}_{90 \%}<15 \mathrm{~s}\right)$, but the ending absorbance appeared to have a rising trend. This rising phenomenon can be more clearly seen in the enlarged diagrams in Figure 6 and was not found to be due to the change of the reagent blank (all reagent blanks were $<0.001$ at $10 \mathrm{~min}$ ).

There are four samples shown in Figure 6 with three tested concentrations $(10,30$ and $50 \mu \mathrm{M} \mathrm{P})$ in freshwater and the last one was $30 \mu \mathrm{M} \mathrm{P}$ in seawater. At $45^{\circ} \mathrm{C}$ the absorbance for a $10 \mu \mathrm{M}$ P sample was 0.198 at $30 \mathrm{~s}$ and rose to 0.204 at $400 \mathrm{~s}$, with a difference as large

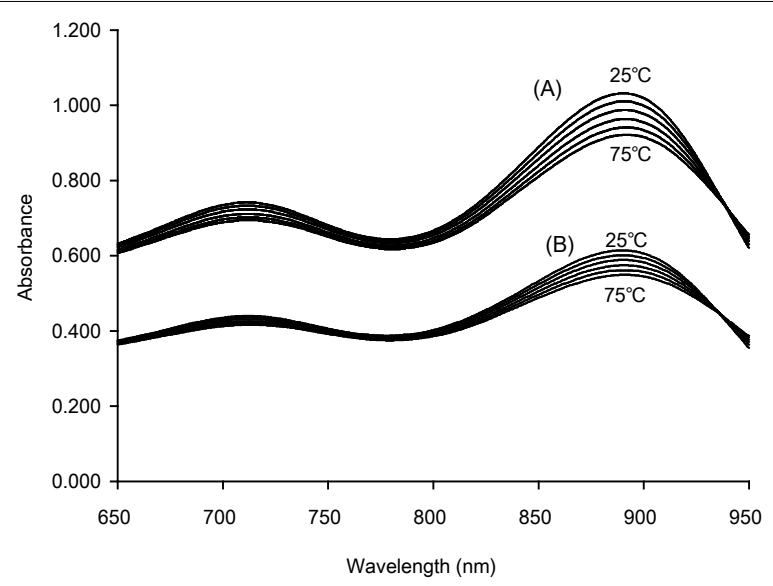

Figure 2: Overlapped spectra of the phosphomolybdenum blue complex at various temperatures for (A) $50 \mu \mathrm{M} P$ in freshwater and (B) $30 \mu \mathrm{M} P$ in seawater. The temperature settings were $25,35-75$ ${ }^{\circ} \mathrm{C}$ at $10^{\circ} \mathrm{C}$ intervals.
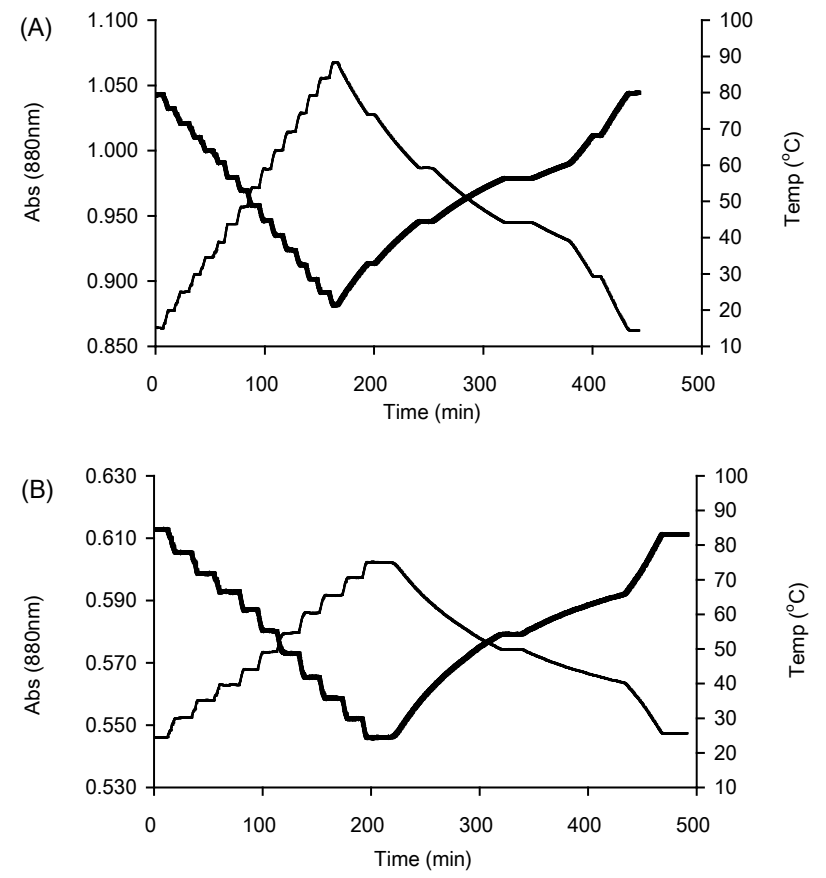

Figure 3: Observation of the variation of absorbance at $880 \mathrm{~nm}$ by changing the temperature of the cuvette holder. (A) $50 \mu \mathrm{M} P$ in freshwater (B) $30 \mu \mathrm{M} \mathrm{P}$ in seawater. 
Citation: Pai S, Wang T, Fang T, Jiann K (2015) Effect of Heating on the Color Formation Reaction in the Murphy and Riley Method for the Determination of Phosphate in Natural Waters. J Environ Anal Chem 2: 139. doi:10.4172/2380-2391.1000139

Page 3 of 4

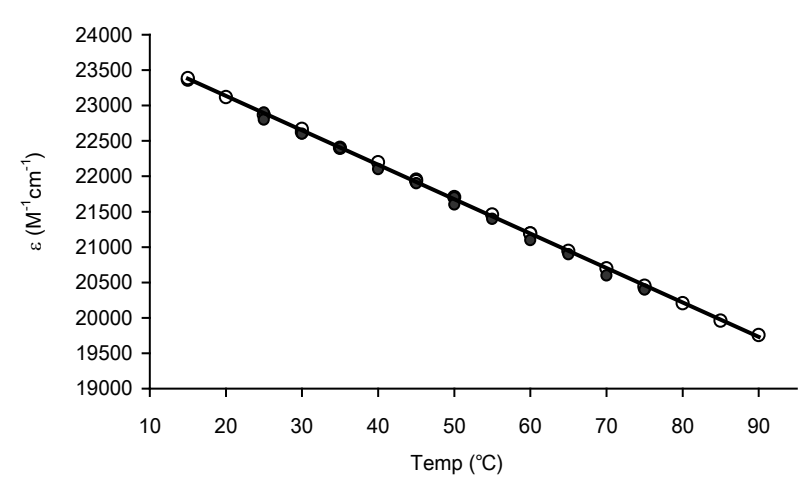

Figure 4: Relationship between the molar extinction coefficient (880 $\mathrm{nm}$ ) and temperature in (circle) freshwater and (dot) seawater. The slope was found to be $-48 \mathrm{M}^{-1} \mathrm{~cm}^{-10} \mathrm{C}^{-1}$ for both media, or a relative trend of $-0.22 \%{ }^{\circ} \mathrm{C}^{-1}$ with respect to $22600 \mathrm{M}^{-1} \mathrm{~cm}^{-1}$ at $30{ }^{\circ} \mathrm{C}$
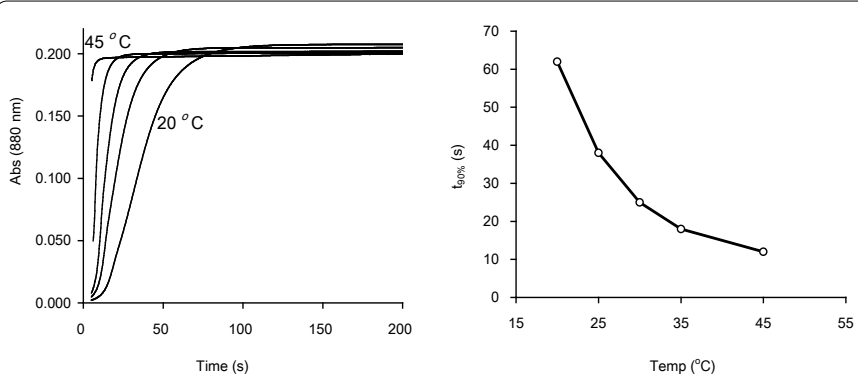

Figure 5: (Left) The color formation curves for a $10 \mu \mathrm{M} P$ solution at 20, 25, 30 , 35 and $45^{\circ} \mathrm{C}$, respectively. (Right) Time required for reaching $90 \%$ of maximum absorbance $\left(t_{90 \%}\right)$ is a function of temperature.

as $+3 \%$ or a slope of $+0.5 \% \mathrm{~min}^{-1}$. This climbing trend continued even after $400 \mathrm{~s}$, and the slope was more obvious at the relatively low concentration comparing to $+0.25 \% \mathrm{~min}^{-1}$ at $30 \mu \mathrm{M}$ and $+0.16 \% \mathrm{~min}^{-1}$ at $50 \mu \mathrm{M}$, respectively. For the seawater medium, the phenomenon was almost the same as for freshwater. It reveals that, the molecular structure of the blue complex might be different if the reaction takes place at a temperature higher than $35^{\circ} \mathrm{C}$. Exp-2 did not continue to add higher temperatures as water vapor started to condense on the wall of the sample bottle.

\section{Reaction at ramped temperatures}

In Exp-3 the sample $(50 \mu \mathrm{M}$ P) was maintained at a fixed starting temperature of $25^{\circ} \mathrm{C}$ and the cuvette holder was heated up by setting the thermostat at $30,45,60,75$ and $90^{\circ} \mathrm{C}$, respectively. The results were somewhat erratic. All curves shown in Figure 7 tangle with each other in the first hour and the readings appear to stabilize only after $180 \mathrm{~min}$. Enlarged diagram (Figure 7) gives a clearer pattern. Only at $30^{\circ} \mathrm{C}$ is the curve in a normal shape. At $45^{\circ} \mathrm{C}$ the blue color formed quickly in $30 \mathrm{~s}$, but dropped a little afterward, and then rose again gradually after $3 \mathrm{~min}$. At $60^{\circ} \mathrm{C}$ the curve dropped after $30 \mathrm{~s}$, rose after $2 \mathrm{~min}$. At $75^{\circ} \mathrm{C}$ the amplitude of the drop-rise became magnified, and after 15 min the absorbance dropped again. At $90^{\circ} \mathrm{C}$ the curve ran high quickly to an absorbance of 1.2 at 7 min which was $+20 \%$ in excess of the normal reading. After $7 \mathrm{~min}$ the absorbance dropped down gradually. The cause of this hump is unclear, and it is not parallel with the reagent blanks which became obvious only at $>75^{\circ} \mathrm{C}$ after 10 min. An extended observation was made by allowing the blue color to form at high temperatures and then cool down to $25^{\circ} \mathrm{C}$. The final absorbance readings did go high but did not go back to the expected values as described in Exp-1. The effect of heating in Exp-3 was no longer reversible.

\section{Conclusion}

The negative aspect of heating on the Murphy and Riley method for the determination of phosphate has long been overlooked by scientists but evidences found in this study reveals that the uncertainty induced by the temperature difference should not be ignored. In general, the molar extinction coefficient of the final blue color at 880
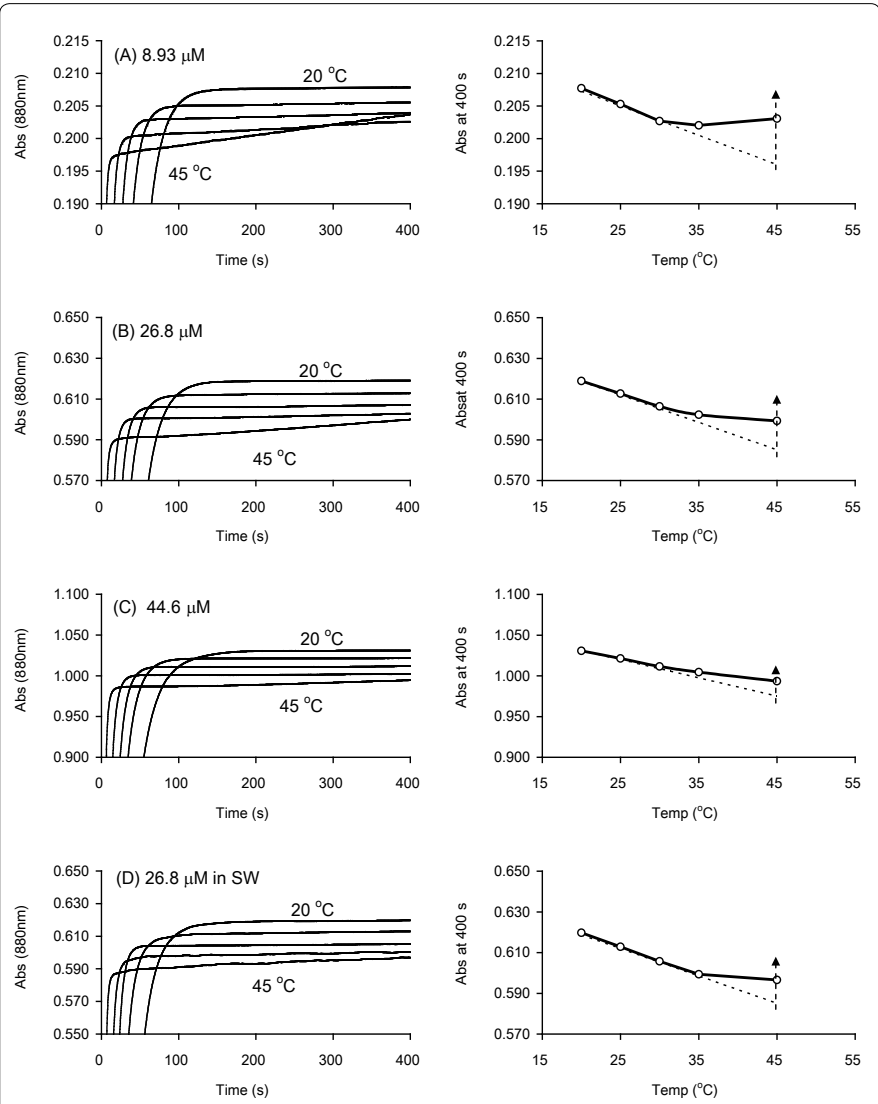

Figure 6: (Left) Enlarged color formation curves of different $P$ concentrations and at various fixed temperatures. (Right) Absorbance at $400 \mathrm{~s}$ as a function of temperature. Arrows indicate the consistent climbing-up of the reading. Dash lines indicate a trend of $-0.22 \%{ }^{\circ} \mathrm{C}^{-1}$. Aliquots of $25 \mathrm{ml}$ of spike samples were added with $3 \mathrm{ml}$ of reagents to give final concentrations of (A) $8.93 \mu \mathrm{M} \mathrm{P}(\mathrm{B})$ $26.8 \mu \mathrm{M} \mathrm{P}(\mathrm{C}) 44.6 \mu \mathrm{M} \mathrm{P}$ in freshwater and (D) $26.8 \mu \mathrm{M} \mathrm{P}$ in seawater.
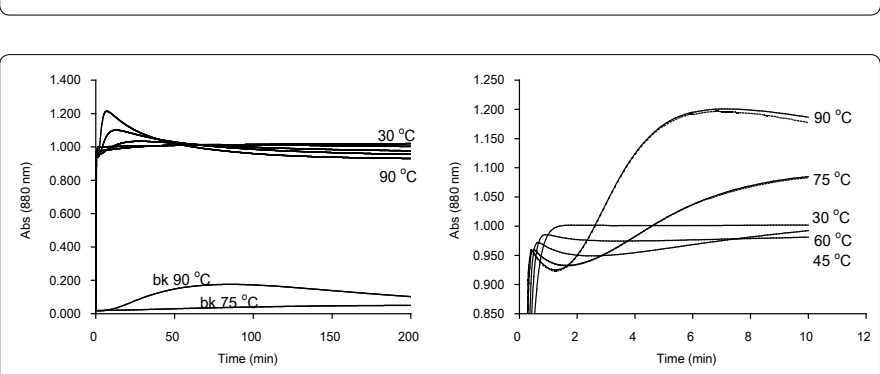

Figure 7: (Left) Color formation curves of a $50 \mu \mathrm{M} \mathrm{P}$ sample (final concentration $44.6 \mu \mathrm{M} \mathrm{P}$ ) with a starting temperature of $25^{\circ} \mathrm{C}$ and ending temperatures of $30,45,60,75$ and $90{ }^{\circ} \mathrm{C}$, respectively. All curves were raw signals without deducting the reagent blanks. Reagent blanks were significant only when the temperature was higher than $75^{\circ} \mathrm{C}$ and $10 \mathrm{~min}$ after the reaction began. (Right) Enlarged diagram showing the change in the first $10 \mathrm{~min}$, with dash lines indicating the reagent blank-deducted curves. 
Citation: Pai S, Wang T, Fang T, Jiann K (2015) Effect of Heating on the Color Formation Reaction in the Murphy and Riley Method for the Determination of Phosphate in Natural Waters. J Environ Anal Chem 2: 139. doi:10.4172/2380-2391.1000139

$\mathrm{nm}$ has an inverse relationship with temperature. If the color formation reaction takes place at temperatures much higher than $35^{\circ} \mathrm{C}$, erratic results can happen and it is irreversible even if the solution cools back down to room temperature. The use of heating at more than $35^{\circ} \mathrm{C}$ should be avoided in any case. When a batch of samples having a wide temperature range is to be measured, or when a sample is just digested for total $\mathrm{P}$ measurement, they should be left to equilibrate with the surrounding temperature before adding reagents. For manual operation a temperature-controlled cuvette holder set at a fixed $30^{\circ} \mathrm{C}$ can be used for optimal precision and accuracy. For automated analysis the same cuvette holder can be used to reduce the possible variation due to the temperature effect.

\section{Acknowledgment}

The authors would like to thank B.W. Tang of Shih-Shin Instrument Co. Taipei, Taiwan for his suggestion on cuvette holder. This project was supported by the National Science Council, Taipei, Taiwan under a contract no. NSC-97-2611M-002-002-MY3.

\section{References}

1. Murphy J, Riley JP (1962) A modified single solution method for the determination of phosphate in natural waters. Anal Chim Acta 27: 31-36.

2. Going JE, Eisenreich SJ (1974) Spectrophotometric studies of reduced molybdoantimonylphosphoric acid. Anal Chim Acta 70: 95-106.

3. Elisenreich SJ, Bannerman RT, Armstrong DE (1975) A simplified phosphorus analysis technique. Environ Lett 9: 43-53.
4. Jarvie HP, Withers PJA, Neal C (2002) Review of robust measurement of phosphorus in river water: sampling, storage, fractionation and sensitivity. Hydrol Earth Sys Sci 6: 113-132.

5. Figueras MJ, Inza I, Polo FL, Feliu MT, Guarro J (1996) A fast method for the confirmation of fecal streptococci from M-enterococcus medium. Appl Environ Microbiol 62: 2177-2178.

6. Johnson KS, Petty RL (1982) Determination of phosphate in seawater by flow injection analysis with injection of reagent. Anal Chem 54: 1185-1187.

7. Yuchi A, Ogiso A, Muranaka S, Niwa T (2003) Preconcentration of phosphate and arsenate at sub-ng $\mathrm{ml}^{-1}$ level with a chelating polymer-gel loaded with zirconium (IV). Anal Chim Acta 494: 81-86.

8. Pai SC, Yang CC, Riley JP (1990) Effects of acidity and molybdate concentration on the kinetics of the formation of the phosphoantimonylmolybdenum blue complex. Anal Chim Acta 229: 115-120.

9. Sjosten A, Blomqvist S (1997) Influence of phosphate concentration and reaction temperature when using the molybdenum blue method for determination of phosphate in water. Wat Res 31: 1818-1823.

10. Benson RL, Truong YB, McKelvie ID, Hart BT (1996) Monitoring of dissolved reactive phosphorus in wastewaters by flow injection analysis. Wat Res 30 : 1959-1964.

11. Drummond L, Maher W (1995) Determination of phosphorus in aqueous solution via formation of the phosphoantimonylmolybdenum blue complex. Re-examination of optimum conditions for the analysis of phosphate. Anal Chim Acta 302: 69-74.

12. Zhang JZ, Fischer CJ, Ortner PB (1999) Optimization of performance and minimization of silicate interference in continuous flow phosphate analysis. Talanta 49: 293-304 